\title{
ARTICLES
}

\section{THE EFFECTIVENESS OF STRUCTURED TEACHING MODULE ON PREVENTION OF ANAEMIA AMONG ADOLESCENT GIRLS}

\section{Mr. Manish Saxena* I Dr. Rajendra Prasad Sharma**}

*Ph.D Scholar \& Assistant Professor, Upchar College of Nursing, Jaipur, Rajasthan, India.

**Associate Professor, Mahatma Gandhi Nursing College, Jaipur, Rajasthan, India.

\section{ABSTRACT}

$$
\text { DOI: http://doi.org/10.47211/trr.2021.v07i01.001 }
$$

Anemia is a clinical condition that results from an insufficient supply of healthy red blood cells to oxygenate the body's tissue adequately; results in hypoxia ${ }^{1}$. It is a deficiency in the number of erythrocytes, the quantity of hemoglobin and or the volume of packed RBCs. Iron deficiency anemia is a condition due to decreased hemoglobin synthesis. It typically results when the intake of dietary iron is inadequate for hemoglobin synthesis. The findings of this study support the need for Community Health Nurse to conduct health education programme, to increase the knowledge of the adolescent girls regarding prevention of anaemia.

Key words: Anemia, Adolescent Girl, Prevention, Knowledge.

\section{ABOUT AUTHORS:}

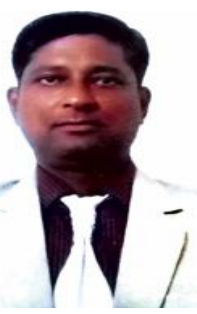

Author Mr. Manish Saxena is working as Associate Professor or Vice Principal at Upchar College of Nursing, Jaipur, Rajasthan, India. He has a Research Guide for PG Programme.

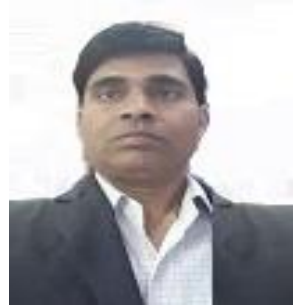

Author Dr. Rajendra Prasad Sharma is working as Associate Professor in Mahatma Gandhi Nursing College, Jaipur, Rajasthan, India. He is a Research Guide for PG and Ph.D. Scholar. He has Presented Papers at Various Seminars and Conferences. 


\section{INTRODUCTION}

Anemia is a condition in which the number of red blood cells or the amount of hemoglobin is low. Red blood cells contain hemoglobin protein that it enables them to carry oxygen from the lungs and deliver it to all parts of the body. When the number of red blood cells is reduced or the amount of hemoglobin in them is low, the blood cannot carry an adequate supply of oxygen. An inadequate supply of oxygen in the tissues produces the symptoms of anemia. ${ }^{3}$

Even there are many blood disorders; anemia is most prevalent nutritional disorders in the world today. Every red blood cell in the body contains iron in its hemoglobin, the pigment that carries oxygen to the tissues from the lungs. But a lack of iron in the blood can lead to anemia, which is a very common nutritional deficiency in children \& adolescents

Anemia is widely prevalent in India and affects both sexes and all age groups1. In India, pre-adolescent and adolescent girls, who constitute a sizable segment of its population, constitute a vulnerable group on account of the practice of early marriages and potential exposure to a greater risk of morbidity and mortality. Adolescence is a crucial developmental period. In adolescent girls on a marginal diet, iron deficiency may be a routine consequence of growth and skeletal development. Further, low iron stores throughout childhood may contribute to a delayed menarche and impaired immune response

\section{NEED FOR THE STUDY}

Anaemia afflicts an estimated two billion people worldwide, mostly due to iron deficiency. It primarily affects women. ${ }^{1}$ yet among adolescents, prevalence rates of anemia are closer for males and females in some parts of the world. The prevalence of anemia is disproportionately high in developing countries, due to poverty, inadequate diet, certain diseases, pregnancy and lactation, and poor access to health services. Young people are particularly susceptible because of their rapid growth and associated high iron requirements.

\section{OBJECTIVES OF THE STUDY}

- To assess the knowledge on prevention of anaemia among adolescent girls before intervention in control and experimental group.

- To find out the effectiveness of structured teaching module on prevention of anemia among adolescent girls in control and experimental group after intervention.

- To find out the effectiveness of structured teaching module on prevention of anemia between control and experimental group after intervention.

- To find out the association between the posttest knowledge scores on prevention of anaemia and

\section{HYPOTHESIS} selected demographic variables of adolescent girls in experimental group.

$\mathbf{H}_{01}$ : There is no significant difference between pre test and post test knowledge scores on prevention of anemia among adolescent girls in control and experimental group.

$\mathbf{H}_{\mathbf{0 2}}$ : There is no significant difference between knowledge scores of control group and experimental group regarding prevention of anaemia among adolescent girls.

$\mathbf{H}_{03}$ : There is no significant association between post test knowledge scores on prevention of anemia and demographic variables of adolescent girls in experimental group.

\section{CONCEPTUAL FRAME WORK}

\section{INDIVIDUAL'S CHARACTERISTICS AND EXPERIENCE:-}

The investigator has included subjects from the school, in rural Bangalore where the individuals character and experience was taken into consideration related to the individual responses to the personal, biological, psychological and sociological feature were taken including the demographic variables like age, type of family, religion, income, education of the parents

\section{BEHAVIOUR SPECIFIC KNOWLEDGE AND AFFECT:-}

The investigator has assessed the specific knowledge and its affect related to the prevention of anemia on the major aspects like general information etiology, symptoms, management and its prevention. The above mentioned aspects may be the modifying factors in the prevention of anemia.

\section{BEHAVIOURAL OUTCOME:-}

The investigator had introduced the structure teaching module to the adolescent girls in selected rural schools by booklet teaching and explaining with the help of charts and models example: - charts and the further assessed their knowledge in the form of planned action and health promotion behaviour.

a. Effective outcome: - An increase in the score related to the knowledge indicates the effective outcome related to health promoting behaviour.

b. Negative outcome: - A decreased score in knowledge aspect indicates the ineffective outcome related to health promoting behaviour that is indicate the re-assessment and intervention. 
RESEARCH DESIGN: -

The true experimental design was used to find out the effectiveness of structure Teaching Module on prevention of anaemia among adolescent girls

It includes manipulation, control and randomization.

\begin{tabular}{|l|l|l|l|}
\hline Group & Pre -test & Intervention & Post- test \\
\hline Experimental & $\mathrm{O}_{1}$ & $\mathrm{X}$ & $\mathrm{O}_{2}$ \\
\hline Control & $\mathrm{O}_{1}$ & - & $\mathrm{O}_{2}$ \\
\hline
\end{tabular}

\section{Table- 1 SCHEMATIC REPRESENTATION OF THE RESEARCH DESIGN}

Key: - $\quad \mathrm{O}_{1}=$ Pre test on knowledge on prevention of anaemia

$\mathrm{O}_{2}=$ Post test on knowledge on prevention of anaemia

$\mathrm{X}=$ Structured Teaching module

RESULT

The results of this study shows that pre-test percentage knowledge on prevention of anaemia in the experimental group 5.93 (14.82\%) of the adolescent girls were having the knowledge of prevention of anaemia and in the control group 6.37 (15.92\%) of the adolescent girls were having the knowledge of prevention of anaemia. Post-test Knowledge of the adolescent girls in the experimental group is $28.40(71.00 \%)$. And in the control group only 7.13(17.82\%) of the adolescent girls were having the knowledge on prevention of anaemia. Hence comparison in pre-test and post-test percentage of prevention of anaemia knowledge of the experimental group of the adolescent girls were having $56.18 \%$ difference during assessment. Whereas in the control group $1.90 \%$ of the adolescent girls were having difference between pre-test and post- test assessment In the experimental group the difference among adolescent girls between pre-test and post-test and knowledge score is significant and statistical significance was tested by paired ' $\mathrm{t}$ ' test ( $\mathrm{P} \& \mathrm{It}$; 0.001 ). There is a significant association between post-test knowledge score in the experimental group and in the demographic data like mother's education and type of family of the adolescent girl.

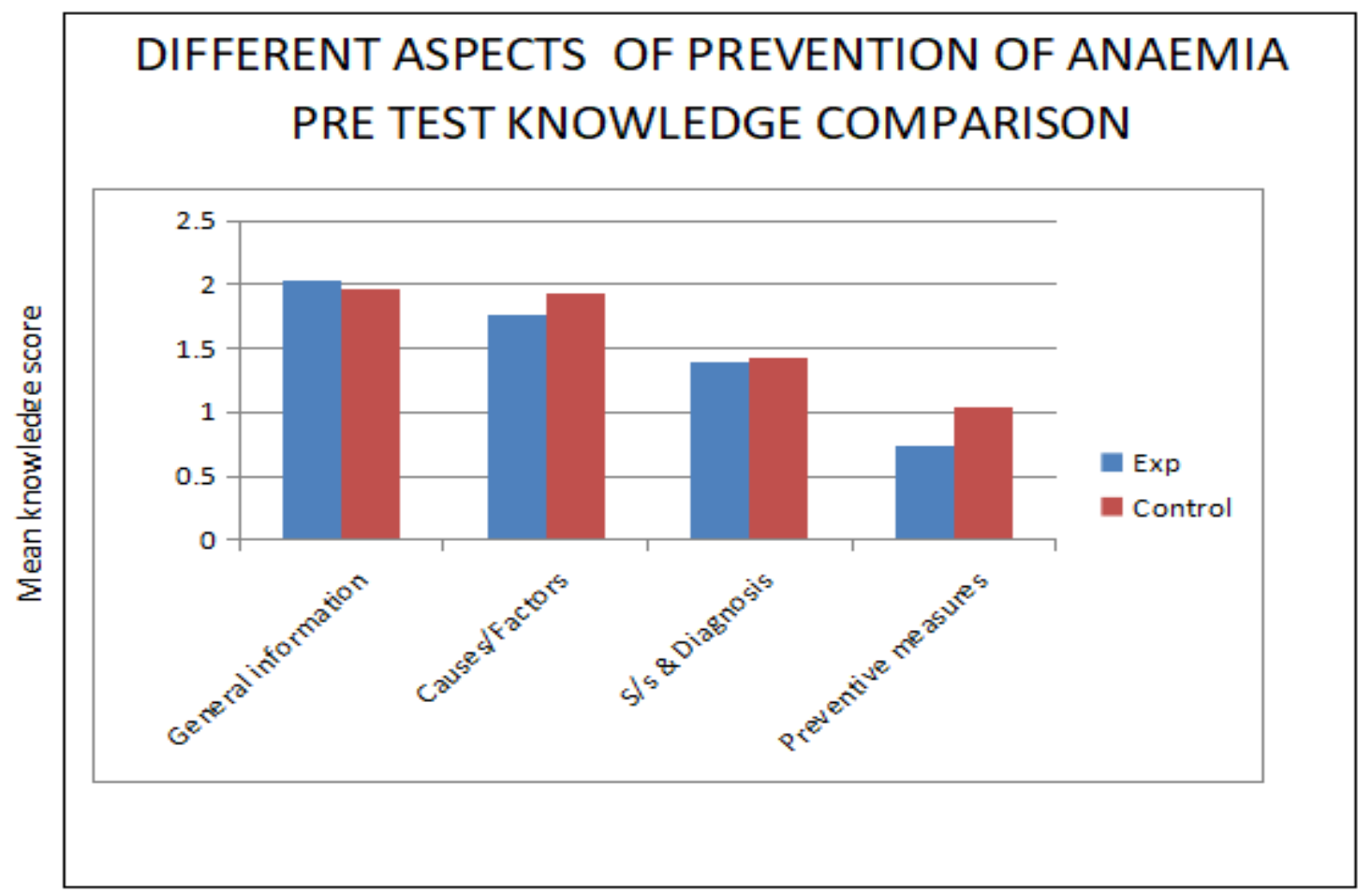

Figure-1 : Multiple bar diagram showing distribution of different aspects on prevention of anaemia pre-test knowledge comparison. 


\section{ARTICLES}

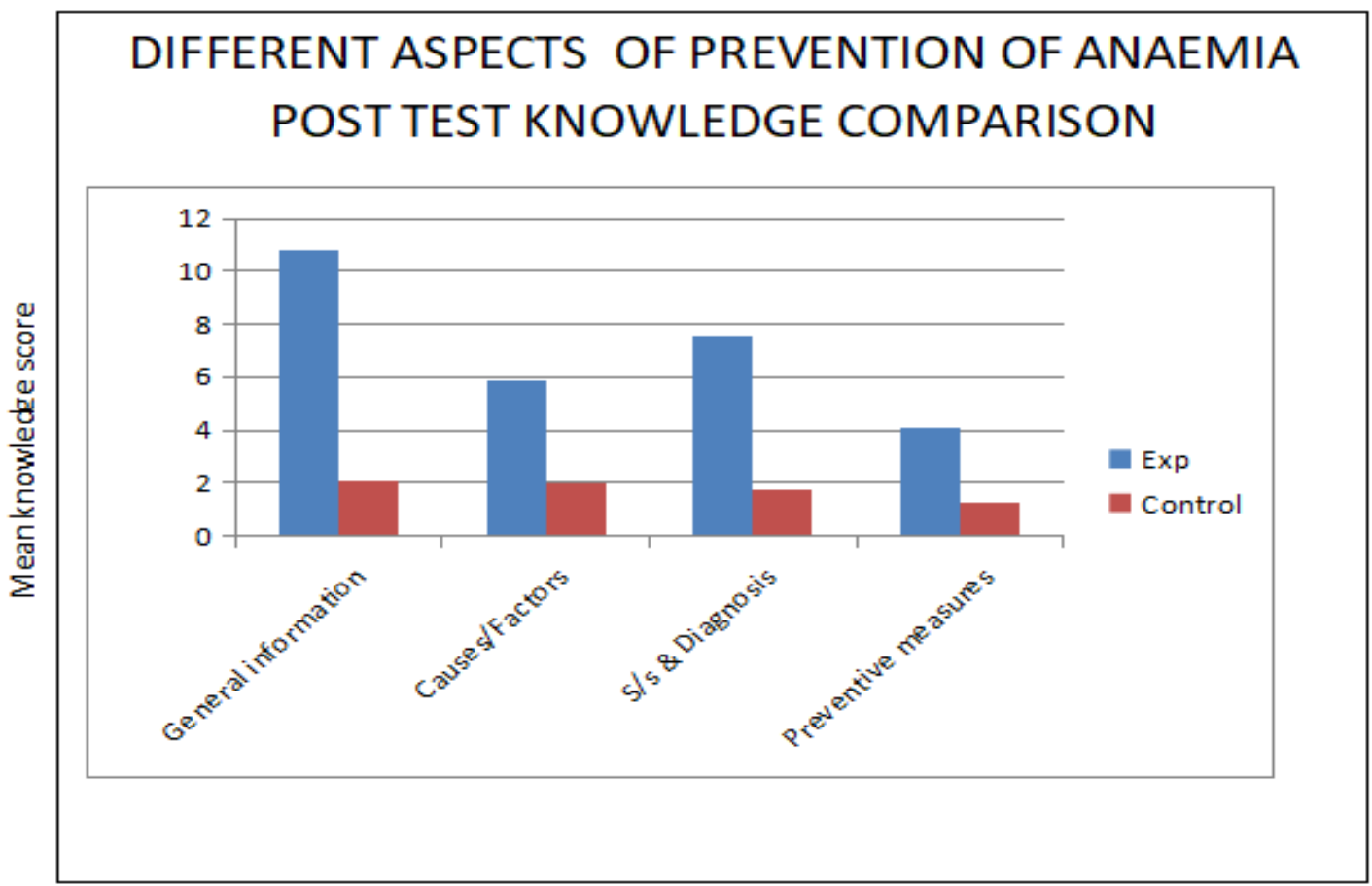

Figure-2 : Multiple bar diagram showing distribution of different aspects on prevention of anaemia post-test knowledge comparison.

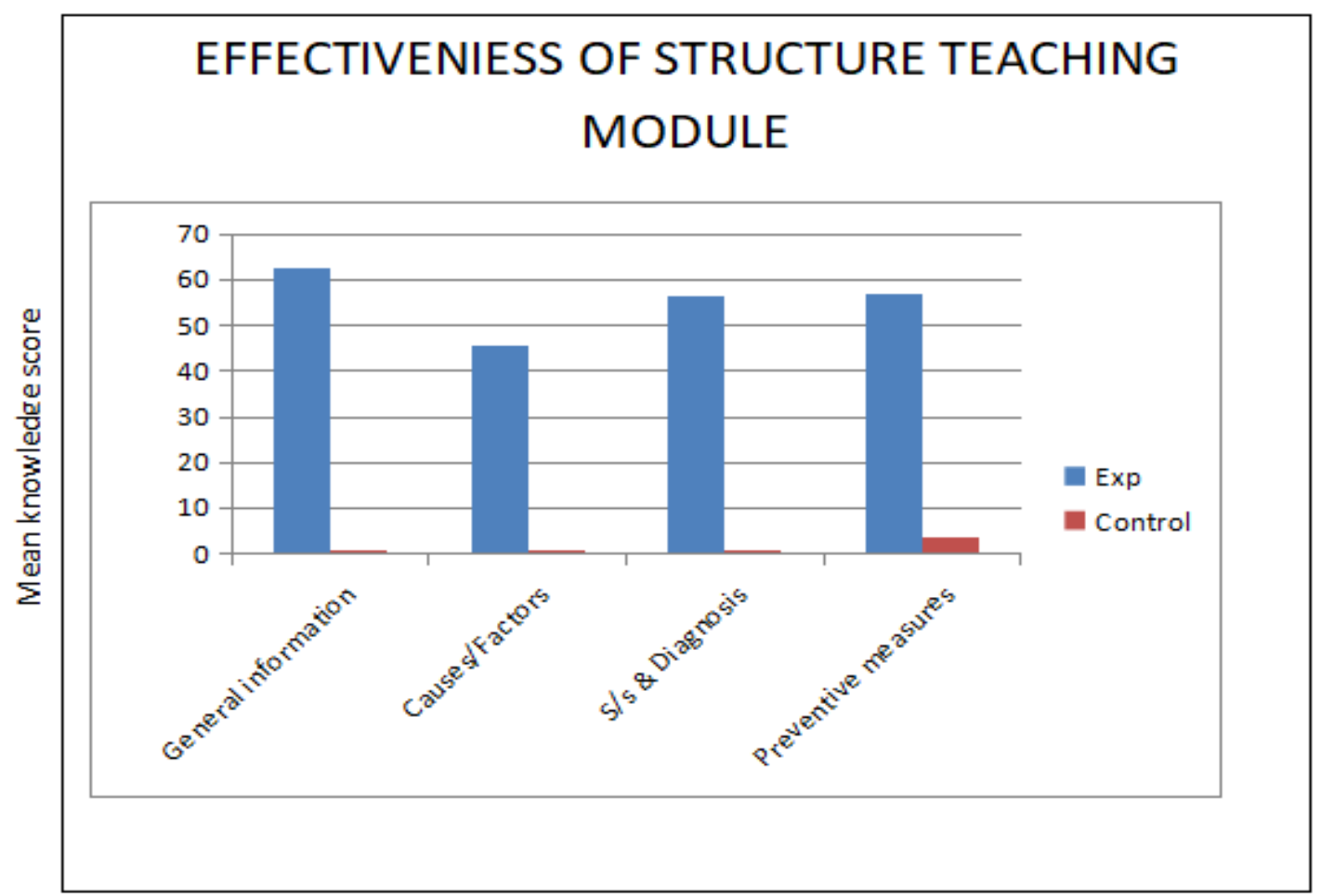

Figure-3: Multiple bar diagram showing distribution of prevention of anaemia knowledge gain score comparison. 


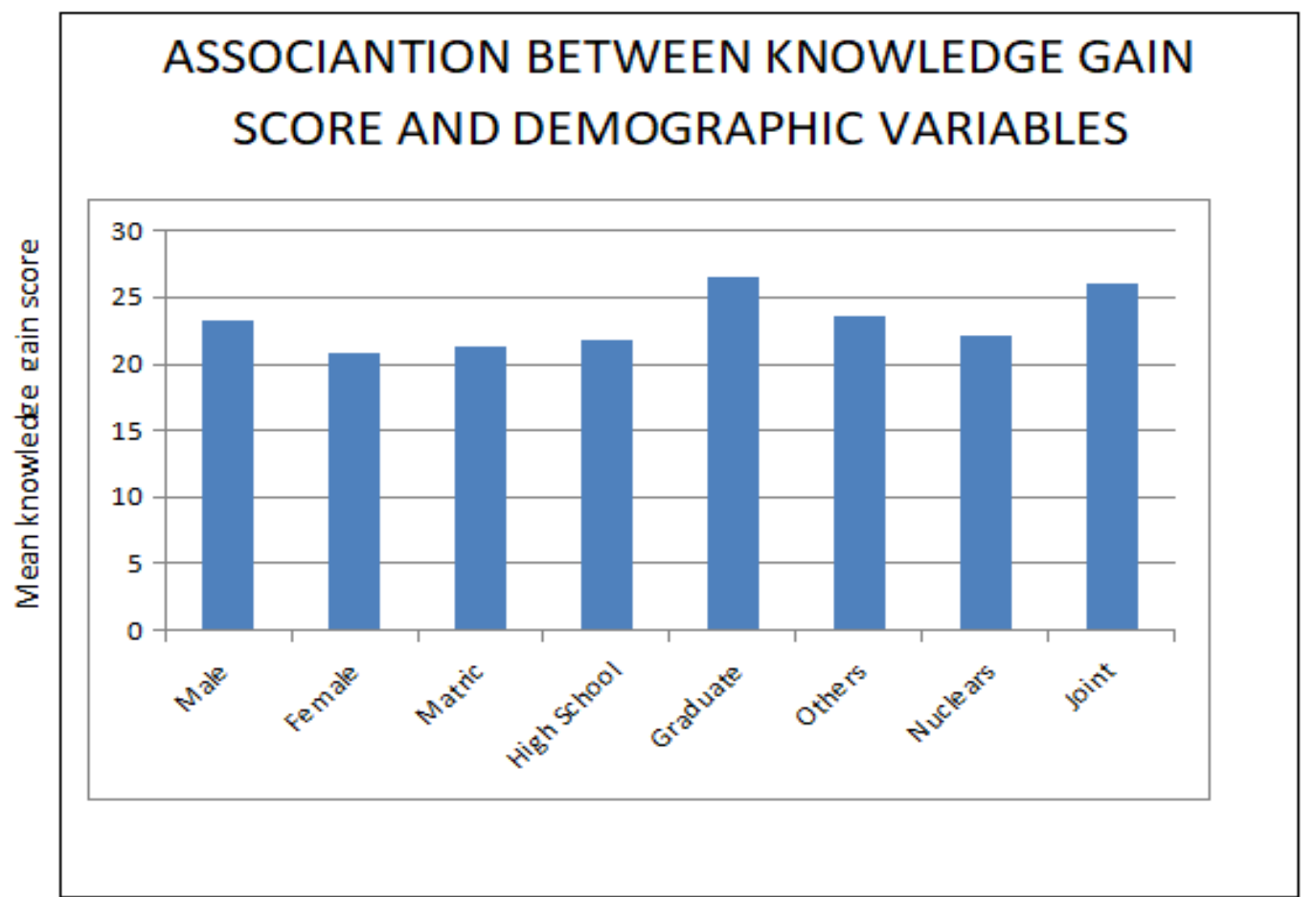

Figure-4: Multiple bar diagram showing distribution of association between knowledge gain score and demographic variables

\section{CONCLUSION}

The findings of this study support the need for Community Health Nurse to conduct health education programme, to increase the knowledge of the adolescent girls regarding prevention of anaemia. This study has proved that the adolescent girls had a remarkable increase in the knowledge regarding prevention of anaemia and when compared to their previous knowledge, prior to the administration of the structure teaching module. Thus for future there is a need to improve their knowledge by conducting the health awareness programme and also by modifying the individual and behavioural factors of the adolescent girls in the community regarding prevention of anaemia.

\section{REFERENCES}

1. Lewis, Heitkemper, Dirksen. Textbook of medical surgical nursing. $6^{\text {th }}$ ed. Philadelphia: Mosby Publication; 2006

2. Brunner \& Sidarth Textbook of medical surgical nursing $10^{\text {th }}$ edition Mosbys publication Philadelphia:2008

3. World Health Organization. Pregnancy and abortion in adolescence. Geneva: WHO, 1975; 583.

4. World Health Organization. Programming for adolescent health and development WHO Tech Rep Ser No. 886, 1996. p. 2. 